\title{
PHASE INVERSION OF COLOURED PICKERING EMULSIONS STABILIZED BY ORGANIC PIGMENT PARTICLE MIXTURES
}

\author{
Bernard P. Binks* and Samuel O. Olusanya
}

School of Mathematics and Physical Sciences, University of Hull, Hull HU6 7RX, U.K.

Submitted to:

Langmuir on 6.3.18; revised on 13.4.18

Contains ESI

*Correspondence to: Prof. B.P. Binks

b.p.binks@hull.ac.uk 


\begin{abstract}
Pickering emulsions stabilized by a mixture of coloured organic pigment particles of different hydrophobicity have been investigated at equal oil:water ratio and a fixed overall particle concentration by several complementary methods. Transitional phase inversion of emulsions from water-in-oil to oil-in-water can be effected by increasing the fraction of hydrophilic pigment orange in mixtures with either hydrophobic pigment yellow, red, indigo or blue. In two mixtures, we find that a distinct change in the colour of emulsions occurs at phase inversion. Although the fraction of pigment orange required depends on the particular hydrophobic pigment selected, phase inversion occurs at a similar surface energy of the particle mixture which lies between that of the hydrophilic pigment and those of the hydrophobic pigments. We show that both pigment types are present at the oil-water interface simultaneously giving rise to emulsions which are extremely stable to coalescence. The average drop size for both emulsion types increases towards phase inversion in line with an increase in the extent of sedimentation/creaming at long time.
\end{abstract}




\section{Introduction}

Following the discovery by Pickering ${ }^{1}$ and Ramsden ${ }^{2}$ over a century ago that particles of nanometer or micrometer size can adsorb at the oil-water interface there has been a resurgence of interest in this area recently. ${ }^{3}$ Emulsions stabilized solely by particles are coined Pickering emulsions, and a variety of particles including silica, ${ }^{4}$ protein, ${ }^{5}$ clay, ${ }^{6}$ microgel ${ }^{7}$ and inorganic pigments ${ }^{8-11}$ have been shown to be effective emulsifiers of oil and water. The type of emulsion formed is determined principally by the wettability of the particle which, for a spherical particle, can be quantified by the three-phase contact angle measured into the aqueous phase. ${ }^{12-14}$ The oil-water contact angle, $\theta_{\text {ow }}$ is related to the solid-oil tension, $\gamma_{s o}$, solid-water tension, $\gamma_{s w}$ and oil-water interfacial tension, $\gamma_{o w}$ by Young's equation:

$$
\cos \theta_{o w}=\frac{\gamma_{s o}-\gamma_{s w}}{\gamma_{o w}}
$$

The magnitude of $\theta_{\text {ow }}$ can be influenced by the roughness of the particle surface either by making the particle more hydrophobic (if $\theta_{\text {ow }}$ is greater than $90^{\circ}$ ) or more hydrophilic (if $\theta_{\text {ow }}$ is less than $90^{\circ}$ ). Using relatively hydrophobic particles, water-in-oil (w/o) emulsions are preferred. ${ }^{15}$ By contrast, for relatively hydrophilic particles, oil-in-water $(\mathrm{o} / \mathrm{w})$ emulsions are produced. ${ }^{16}$ The conversion from water-in-oil to oil-in-water emulsions and vice versa can be achieved either by varying the water volume fraction (catastrophic phase inversion) ${ }^{17}$ or by changing properties that affect the particle wettability (transitional phase inversion). ${ }^{18-20}$ The vast majority of studies involving Pickering emulsions refer to systems containing only one particle type; very few studies have been involved with mixtures of particles.

Emulsion phase inversion can also be effected by mixing two particle types of different hydrophobicity. Using mixtures of fumed silica particles, Binks and Lumsdon ${ }^{21}$ showed that transitional phase inversion can be induced by varying the weight fraction of one of the particle types at constant total particle concentration or by the addition of hydrophilic silica to w/o emulsions stabilized initially by hydrophobic silica particle and vice versa. The emulsions formed were very stable to coalescence although the stability to creaming of o/w emulsions and to sedimentation of w/o emulsions decreased towards the phase inversion composition. Recently, Saha et al. ${ }^{22}$ have described the in situ assembly of two non-surface active particle types (silica and carbon) of different hydrophobicity in stabilizing emulsions. By varying the proportion of the two particle types or the water volume fraction, both types of emulsion were successfully produced. An alternative strategy has been to mix oppositely charged particles which form various kinds of heteroaggregate possessing sufficient surface activity to enable emulsion stabilization. Examples include mixtures of polystyrene 
particles, ${ }^{23}$ polymer microgels, ${ }^{24}$ clay + layered double hydroxide particles ${ }^{25}$ and mixtures of other latex particles. ${ }^{26}$ In addition, the arrangement of particle mixtures at air-water or oil-water interfaces or in 2D has been studied both experimentally ${ }^{27-30}$ and theoretically. ${ }^{30-32}$ Using confocal laser scanning microscopy, Dai et al. ${ }^{33}$ probed the structure formed by a mixture of sulphate-treated polystyrene particles (hydrophobic) and carboxylic-treated polystyrene particle (hydrophilic) around silicone-inwater emulsion droplets. Similarly, Ma and $\mathrm{Dai}^{34}$ studied the interfacial structure formed by mixed polystyrene particles surrounding ionic liquid-in-water emulsion drops.

The major goal of the present work is to investigate the type and colour of Pickering emulsions stabilized by a mixture of coloured organic pigment particles using equal volumes of $n$-heptane and water. Colour is one of the optical properties which is very important in determining the perceived quality of emulsion-based products. ${ }^{35-39}$ These properties depend on how a substance interacts with electromagnetic radiation in the visible region either through scattering ${ }^{40}$ or absorption ${ }^{41}$ which are controlled by the inherent properties of the emulsion droplets (e.g. size and refractive index) and the presence of any colourant. Colour is developed when an emulsion absorbs a certain wavelength of light in the visible region, which may be due to the presence of colourant either in the dispersed or continuous phase of the emulsion. ${ }^{35}$ Colourants can be dyes or pigments. Pigments are particulate materials that have colour imparting ability and they are insoluble in their medium of application. ${ }^{42-44}$ Pigments are commonly used as colour imparting agent in many industrial applications ${ }^{45-47}$ and also in a range of technological applications such as electronics and reprographics. ${ }^{48-50}$ However, little is known about their emulsifying ability.

Despite reports describing the stabilization of Pickering emulsions using inorganic pigments ${ }^{8-}$ ${ }^{11}$, studies on emulsions stabilized by organic pigment particles are rare. Recently, using the powdered particle method, we have shown the possibility of forming both w/o and o/w emulsions using coloured organic pigment particles as sole emulsifier and we observed that the colour of the emulsions was similar to that of the pigment used. ${ }^{51} \mathrm{We}$ presented evidence for the link between the tendency of an emulsion to phase invert catastrophically and the surface energy of the pigment for a range of seven pigments. In this work, we show that both stable water-in-heptane and heptane-in-water emulsions can be produced using a mixture of coloured organic pigment particles of different hydrophobicity. We demonstrate transitional phase inversion of emulsions by varying the weight fraction of the hydrophilic pigment in the mixture at constant total particle concentration. Emulsions formed are characterized using the drop test, conductivity, optical microscopy and cryo-SEM analysis. We link the propensity of the emulsions to phase invert to the oil-water contact angle and the pigment surface energy. 


\section{Experimental}

\section{Materials}

The water used was passed through an Elga reverse osmosis unit and then a Milli-Q reagent water system. The oil used is $n$-heptane (Sigma, 99\%). It was columned twice using basic alumina (Merck) to remove polar impurities. The liquids used for the estimation of pigment surface energy are glycerol (Sigma Aldrich, 99\%), formamide (Sigma Aldrich, $\geq 99 \%$ ), $\alpha$-bromonaphthalene (Sigma Aldrich, > 97\%) and hexadecane (Sigma Aldrich, > 99\%). The five organic pigments used were received from BASF (Germany) and their chemical formula and several properties are given in Table S1. Red pigment, PR (Irgalite Red D 3707) and orange pigment, PO (Cromophtal Orange K 2960) are mono azo pigments with an average primary diameter of 0.16 and $0.18 \mu \mathrm{m}$ respectively. Yellow pigment, PY (Paliotol Yellow K 0961) is a quinophthalone pigment with a diameter of $0.17 \mu \mathrm{m}$. Blue pigment, PB (Heliogen Blau K 6907) is a phthalocyanine with a diameter of $0.44 \mu \mathrm{m}$ whilst indigo pigment, PI (Cromophtal Violet D 5700) is a dioxazine pigment of diameter $0.15 \mu \mathrm{m}$. Pigment orange, PO is relatively hydrophilic whilst the other four pigments are more hydrophobic. The four particle mixtures considered are POPR, POPY, POPI and POPB.

\section{Methods}

\section{(i) Contact angles on pigment particle disks}

For oil-water-solid contact angle measurements, disks were made from the pigment particle mixtures POPB and POPR containing different weight fractions of PO, WPO. For determination of the apparent surface energy of pigment mixtures, disks were made from different pigment particle mixtures at a WPO around the emulsion phase inversion composition ( $\mathrm{WPO}=0.42,0.32,0.22$ and 0.12 for POPR, POPY, POPI and POPB respectively). The disks were made by compressing $250 \mathrm{mg}$ of the dry pigment powder in a steel die with diameter $13 \mathrm{~mm}$ using a hydraulic press (Research and Industrial Instrument Co., UK) and a pressure of $8.0 \times 10^{8} \mathrm{~N} \mathrm{~m}^{-2}$. Prior to disk formation, the particles were thoroughly mixed together with a magnetic stirrer (Corning PC 420D) in a capped vial. The oil-water and airliquid contact angles were measured using the sessile drop technique with a Krüss DSA Mk 10 apparatus. For surface energy determination, the advancing contact angle of a drop of water or other liquid in air was measured by placing $10 \mu \mathrm{L}$ on the surface of the particle disk and thereafter the receding contact angle was measured after withdrawing $3 \mu \mathrm{L}$ of liquid from the drop. The advancing oil-water contact angles were measured under $n$-heptane by placing the disk in a cubic quartz cell (dimension $2 \times 2 \times 2 \mathrm{~cm}$ ) and adding $3 \mathrm{~cm}^{3}$ of oil. Thereafter, a drop of water was gently placed on 
the surface of the disk and the contact angles (advancing and receding) were measured. The profiles of the drops were obtained separately and analyzed and the average of at least three contact angles was recorded. ${ }^{52}$

\section{(ii) Particle mixture immersion test}

The wetting behaviour of pigment particle mixtures was investigated by placing $50 \mathrm{mg}$ of pigment made at two different $\mathrm{WPO}_{\mathrm{PO}}(0.1$ and 0.6$)$ on the surface of either $3 \mathrm{~cm}^{3}$ of water or $n$-heptane at room temperature. It was observed if the particle mixture immersed in the liquid or not. After $2 \mathrm{~h}$ the mixture was vigorously hand shaken for $30 \mathrm{~s}$ and the formation of either a dispersion, foam or climbing film was noted. The colour of the resulting mixture was also noted. Prior to the immersion test, the particle mixtures were made by measuring the required mass of the two pigments in a screw cap vessel followed by hand shaking.

\section{(iii) Preparation of emulsions}

Preferred emulsions were prepared using the powdered particle method ${ }^{53}$ using a mixture of pigment particles of different hydrophobicity. Emulsions containing equal volumes of water and $n$-heptane were made at a constant total pigment concentration of $1 \mathrm{wt} . \%$ but with a varying weight fraction of the hydrophilic pigment $\mathrm{PO}$, i.e. $\mathrm{WPO}=$ mass $\mathrm{PO} /($ mass $\mathrm{PO}+$ mass other pigment $)$. The required mass of the pigment particle mixture was placed in a $14 \mathrm{~cm}^{3}$ screw cap glass vessel (diameter $1.8 \mathrm{~cm}$, height $7.2 \mathrm{~cm}$ ). Water was then added followed by $n$-heptane and the mixture was homogenized with an IKA digital Ultra Turrax T25 homogenizer with $8 \mathrm{~mm}$ head operating at 12,000 rpm for $2 \mathrm{~min}$.

\section{(iii) Characterization of emulsions}

Photographs of the vessels containing the emulsions were taken with a Canon camera IXUS 170. The drop test was used to confirm the emulsion type. Oil continuous emulsions dispersed in $n$-heptane and remained as drops in water (i.e. w/o emulsion) and vice versa. The conductivity of the emulsion was measured using a Jenway 4310 digital conductivity meter equipped with Pt/Pt black electrodes. The stability of o/w emulsions to creaming was assessed by monitoring the increase with time of the position of the water-emulsion interface, whereas the extent of coalescence was determined from the movement of the oil-emulsion boundary. For w/o emulsions, the downward movement of the oilemulsion boundary was used as a measure of the stability to sedimentation while the position of wateremulsion interface was used as an indicator of coalescence. ${ }^{53}$ The fraction of oil $\left(f_{o}\right)$ or water $\left(f_{w}\right)$ released refers to the volume of oil or water released relative to the initial volume of oil or water used in the preparation of the emulsion. 
Optical microscopy of the emulsions was obtained with an Olympus BX51 microscope fitted with a CCD camera system DP70. The images were processed with Image-Pro Plus 6.0 software. A drop of emulsion was taken from the centre of the emulsion layer and diluted with the appropriate continuous phase. The average diameter of the droplets was determined with Image $\mathrm{J} 1.47 \mathrm{v}$ by measuring the size of 50 droplets in the digital micrographs. For cryo-scanning electron microscopy (SEM) analysis, a small sample of the emulsion was pipetted onto an aluminium sample mount and plunged into liquid nitrogen at $-170{ }^{\circ} \mathrm{C}$. Using a transfer rod, the sample was placed in the preparatory chamber stage (PP3010T Quorum Technologies) at an operating temperature of $-140{ }^{\circ} \mathrm{C}$. Then the sample was fractured and thereafter transferred to a Zeiss EVO 60 SEM chamber where the oil was sublimed. It was then returned to the preparatory chamber where it was coated with $\mathrm{Pt}(2 \mathrm{~nm})$. It was transferred again into the SEM stage for viewing and imaging at $-140{ }^{\circ} \mathrm{C}$. Different areas at the droplet surface were imaged and the elemental composition of the particles in these areas were analyzed using energydispersive X-ray spectroscopy (EDX).

All experiments are performed at room temperature $\left(21 \pm 2{ }^{\circ} \mathrm{C}\right)$.

\section{Results and discussion}

We first describe the appearance of dry pigment particle mixtures and their mixtures with either water or $n$-heptane. We then present evidence for transitional phase inversion of emulsions induced by varying WPO $_{\mathrm{P}}$ in mixtures with four other pigment types. Emulsion stability, average droplet sizes and the arrangement of particles on droplet interfaces are discussed. Oil-water-solid contact angles are used to understand phase inversion. Finally, we link the emulsion behaviour to the apparent surface energy of the dry pigment particle mixture.

\section{(a) Dry pigment particle mixtures and their immersion in liquids}

Five pigments (PO, PR, PY, PI and PB) out of the seven pigments used previously ${ }^{51}$ were selected. Pigment PO is more hydrophilic while the other four pigments are more hydrophobic. We found earlier that $1 \mathrm{wt} . \%$ of particles was sufficient to produce preferred emulsions which were very stable to coalescence. Photos of the vessels containing pigment particle mixtures at different weight fractions of PO are given in Figure 1(i) for POPR, POPY, POPI and POPB respectively. For the mixture POPR (a), only a slight change in colour is observed from red through reddish-orange to orange on increasing WPO. For the mixture POPY (b), a progressive change in colour from yellow through orange-yellow, 
yellowish-orange to orange occurs. In the POPI mixture (c), a progressive colour change from indigo through dark brown to orange occurs. In the case of the POPB mixture (d), the blue colour dominates up to $\mathrm{W}_{\mathrm{PO}} \geq 0.8$ however even though the colour brown is expected. When mixtures of PO and PR are compressed into a disk, a similar progression in colour is seen on increasing WPO as with the mixed powders, Figure 1(ii).

We investigated the behaviour of pigment particle mixtures added to liquid surfaces by placing $50 \mathrm{mg}$ of powder on $3 \mathrm{~cm}^{3}$ of either water or $n$-heptane. As seen in Figure 2 for two values of wpo, at rest all the particle mixtures are spontaneously wetted by $n$-heptane and sediment. By contrast, in water only pigment PO was spontaneously wetted yielding a dispersion with the other three pigments separating from the powder and remaining on its surface. For the pigment particles to interact well with the solvent, air in the powders was expelled by agitating the vessels for $30 \mathrm{~s}$. Turbid dispersions with sediment were observed for all the particle mixtures in both solvents and, in some cases, their colour is similar to that of the mixed powder. In water, climbing films of colour similar to that of the mixed powder were formed in systems of low WPO (0.1) whilst unstable air-in-water foams containing bubbles coated with mixed particles were formed in systems of high WPO (0.6). Climbing films are formed when air bubbles partially coated with particles coalesce with the planar air-water surface releasing their particles, which causes an increase in their concentration at the planar surface and a concomitant increase in surface pressure causing the film to move upward. ${ }^{54}$ In a solid-liquid system containing one pigment type, the colour of the particle dispersion is always the same as the colour of the pigment used. As seen in Figure 2 for mixtures, in most cases the colour of the particle dispersion depends on $\mathrm{WPO}_{\mathrm{PO}}$ and on the liquid used. For example, at $\mathrm{WPO}_{\mathrm{PO}}=0.1$ for the mixture POPB, the colour of the particle dispersion in water is dark brown whereas it is deep blue in $n$-heptane. This is partly a result of the different refractive index contrast with the two liquids but also because only a small fraction of PB enters water being quite hydrophobic. A question which arises is what will be the colour of emulsions when particles are also adsorbed at oil-water interfaces?

\section{(b) Type of emulsion stabilized by pigment particle mixture}

The possibility of forming stable w/o and o/w simple emulsions using a single pigment was reported by us recently for seven pigment types exhibiting the primary colours of the rainbow (PR, PO, PY, PG, PB, PI and PV). ${ }^{51}$ For $n$-heptane-water emulsions (1:1 by vol.), preferred emulsions were o/w for PO and w/o for the other six pigment types. Emulsion type was consistent with the measured and calculated contact angles of the particles at the oil-water interface. After 3 months, no change in emulsion stability was observed and the stability to coalescence was found to increase with particle 
concentration. Only $0.5 \mathrm{wt} . \%$ of particles was required to yield emulsions stable to coalescence, except for PG and PV-stabilised emulsions so these pigments are not pursued here. Optical microscopy and cryo-SEM images of preferred emulsions stabilized by the five pigments used here are given in Figures $\mathrm{S} 1$ and S2 respectively, where it is clear that these pigment particles may reside at the oil-water interface. Spherical droplets were formed in all cases except for PI where many non-spherical drops are also formed. The mean drop diameter decreases as the concentration of particles increases until a limiting value is attained. Using the theory of the limited coalescence, we determined the fraction of the droplet interface covered by particles. In a few cases, close-packed primary particles formed around emulsion drops whereas a relatively low surface coverage was found in PO-stabilized o/w emulsions, despite them being very stable to coalescence.

We showed recently that the colour of an emulsion stabilized by a single pigment type is the same as the colour of the pigment used. It is of interest to investigate the colour and type of emulsions formed by a mixture of two pigments, which differ in colour and in wettability. Here, we study $n$ heptane-water emulsions stabilized by four different pigment particle mixtures. We use the powdered particle method to prepare them (1:1 by vol.) containing a particle mixture (POPR, POPY, POPI or POPB) at fixed concentration (1 wt.\%) but at varying WPO. Photos of the vessels containing these emulsions are given in Figure 3. From results of the drop test, emulsions rich in the hydrophobic pigment (low WPO) are w/o whereas those rich in the hydrophilic pigment (high $\mathrm{W}_{\mathrm{PO}}$ ) are o/w. The value of WPO at conditions of transitional phase inversion (dashed line) is highly dependent on the particular pigment mixture. Emulsion type has also been verified using conductivity measurements. The conductivities of $n$-heptane and water at $20{ }^{\circ} \mathrm{C}$ are 0.01 and $0.80 \mu \mathrm{S} \mathrm{cm}{ }^{-1}$ respectively. The variation of emulsion conductivity with WPO for the four pigment particle mixtures is given in Figure 4. Low conducting emulsions are w/o whereas those of higher conductivity are $\mathrm{o} / \mathrm{w}$. The dashed lines indicate the position of phase inversion, i.e. $\mathrm{WPO}=0.425,0.325,0.225$ and 0.125 for mixtures of PO with PR, PY, PI and PB respectively. The fact that inversion occurs in the first place is indirect evidence that both pigment types adsorb to droplet interfaces to some extent. Emulsion type is determined by the wettability of the particle mixture at the interface.

In general, w/o emulsions sediment with time leaving a cloudy or clear oil phase above the emulsion. By contrast, o/w emulsions cream leaving a turbid aqueous phase containing non-adsorbed particles. For POPR mixtures (Figure 3(a)), the colour of the emulsions changes from red through reddish-orange to orange upon increasing WPO from 0 to 1 . The first colour change occurs as emulsions invert from w/o to o/w. Comparing Figure 1(i)(a) with Figure 3 (a), it can be seen that the colour of the mixed particles and the mixed emulsions is very similar. This implies that both particle types 
present in emulsions coat droplet interfaces preventing coalescence. For POPY-containing emulsions (Figure 3(b)), all are orange except that prepared at $\mathrm{WPO}_{\mathrm{PO}}=0$ which is yellow. This is different to the case of mixed dry particles, Figure 1(i)(b), where a progressive colour change occurred. The entrapment of excess PO particles inside water drops at low WPO may account for their orange colour. In the case of POPI-containing emulsions (Figure 3(c)), a progressive colour change from indigo through dark brown to orange is observed upon increasing WPO. The major colour change occurs around phase inversion. The close similarities in colour between the mixed emulsions and the mixed dry particles implies that both particle types probably coat droplet interfaces in the former. Finally, for the POPB system (Figure 3(d)), emulsions undergo a change in colour from blue to indigo through dark brown to orange as WPO increases to unity. This is in sharp contrast to the colour of mixed dry particles, Figure 1(i)(d), which remain blue mainly.

\section{(c) Stability and morphology of emulsions stabilized by pigment particle mixture}

For the mixed particle-stabilized emulsions, we have monitored the release of oil due to either sedimentation in w/o emulsions or coalescence of $\mathrm{o} / \mathrm{w}$ emulsions and the release of water as a result of coalescence in w/o emulsions or creaming of o/w emulsions through phase inversion. Figure 5 shows the time course for the release of $n$-heptane (a) and water (b) for the POPI mixture. That for the other mixtures is given in Figure S3. In all cases, the breakdown processes referred to are complete after only 5-6 min, with no further changes for up to 6 months. The stability of the emulsions six months after preparation is expressed in terms of the fraction of oil $\left(\mathrm{f}_{\mathrm{o}}\right)$ or water $\left(\mathrm{f}_{\mathrm{w}}\right)$ resolved, displayed in Figure 6 as a function of WPO. Apart from the w/o emulsion containing the mixture POPB at $\mathrm{WPO}=$ 0.1 , all other emulsions are very stable to coalescence with values of $f_{o}$ and $f_{w}$ being zero in most cases. However, coalescence stability of $\mathrm{o} / \mathrm{w}$ emulsions decreases slightly towards phase inversion, as reported earlier for emulsions stabilized by silica particles of different wettability ${ }^{55}$ For w/o emulsions, the stability to sedimentation decreases slightly towards phase inversion except for POPY mixtures where it remains constant. For o/w emulsions, the stability to creaming also decreases progressively towards phase inversion.

Optical microscopy images of the mixed emulsions soon after preparation are given in Figure 7 for a w/o and o/w emulsion of each mixture and in Figure S4 for other values of wpo. Droplets are spherical in all emulsions except those containing POPI mixtures where non-spherical water drops are formed. The appearance of non-spherical drops in particle-stabilised emulsions is common, e.g. refs. 3, 8, 19 and 53, and occurs during emulsification by shear mixing in which particles become jammed 
on interfaces preventing relaxation of the drop to spherical geometry. We also notice that w/o droplets are discrete before phase inversion whereas o/w droplets are more flocculated after phase inversion for all the particle mixtures studied. The arrangement of particles at droplet interfaces was probed using cryo-SEM analysis. For o/w emulsions, frozen oil was removed by sublimation leaving behind a cavity, whereas in w/o emulsions sublimation of frozen oil makes it possible to view particles around frozen water droplets. Cryo-SEM images of w/o emulsions stabilized by POPY (WPO = 0.3) and POPI $(\mathrm{WPO}=0.2)$ as well as o/w emulsions stabilized by POPR $(\mathrm{WPO}=0.5), \mathrm{POPY}(\mathrm{WPO}=0.6)$ and POPB $\left(\mathrm{W}_{\mathrm{PO}}=0.7\right)$ are shown in Figure 8. Images for other selected compositions are shown in Figure S5. The arrangement of particles at drop interfaces differs depending on emulsion type. For w/o emulsions, particles are invariably close-packed and form a coherent layer between water and oil. By contrast, for $\mathrm{o} / \mathrm{w}$ emulsions, particles form a network with bare areas within. It is likely that many of the particles in these interfaces are charged (zeta potential of PO in water was - $22 \mathrm{mV}^{51}$ ) and repulsion between clusters of particles occurs. A variety of mixed particle clusters of different geometry may exist on droplet interfaces depending on the composition with respect to both pigment types. As shown by Law et al. ${ }^{30}$ for mixtures of micron-sized silica particles of different hydrophobicity spread at a planar oilwater interface, mixed clusters of $\mathrm{AB}_{2}, \mathrm{AB}_{6}$ and even $\mathrm{AB}_{8}$ can form, with $\mathrm{A}$ being the hydrophobic particle and B being the hydrophilic one. Induced by the presence of hydrophobic particles, there exists a strong selective attraction between hydrophobic and hydrophilic particles and a strong repulsion between hydrophilic particles within a cluster. It is worth pointing out however that dilute particle monolayers at planar interfaces and more concentrated particle layers within emulsions may be different in terms of the arrangement of particles within clusters and of the spatial arrangement of neighbouring clusters. The presence of both types of pigment at drop interfaces was confirmed by EDX analysis of particles on parts of the surface. We chose o/w emulsions containing the POPY mixture $(\mathrm{WPO}=0.6)$ or the POPB mixture $(\mathrm{WPO}=0.4)$. From the chemical structure of the pigments given in Table S1, all three pigments contain carbon, nitrogen and hydrogen. In addition, PO contains oxygen, PY contains oxygen and chlorine and PB contains copper. EDX spectra of each of the dry pigments are given in Figure S6 confirming all the elements except hydrogen. The EDX spectra from emulsions are given in Figure S7. For POPY (a), the presence of peaks due to chlorine and for POPB (b) the presence of peaks due to copper provides evidence that both types of pigment reside at the interface. However, the peak due to nitrogen is missing in the spectrum from POPB. For the purpose of comparison, the EDX spectrum of the surface of a water drop in oil stabilized by PB particles alone is given in (c). This spectrum contains the expected peaks except that due to nitrogen. This may be due to insufficient pigment particle counts required for the nitrogen peak to appear. 
Finally, the variation of the mean drop diameter in emulsions with wPO is shown in Figure 9. In general for all four systems, the drop size of both w/o and o/w emulsions increases towards phase inversion and water drops are larger than oil drops in most cases. The change in drop size with WPO correlates with changes in the extent of sedimentation and creaming of w/o and $\mathrm{o} / \mathrm{w}$ emulsions respectively. The average drop diameter of o/w emulsions stabilized by PO alone $(25 \mu \mathrm{m})$ is smaller than that of the w/o emulsions stabilized by the other three pigment types alone.

\section{(d) Oil-water-solid contact angles in pigment particle mixtures}

As seen, transitional emulsion phase inversion from w/o to $\mathrm{o} / \mathrm{w}$ occurs at fixed volume ratio of oil and water upon increasing the weight fraction of PO in mixtures with other pigments. Assuming that the fraction of PO in the mixed particle layer at droplet interfaces also increases with WPO, it is expected that an average contact angle between that for the more hydrophobic pigments and that for PO develops inducing phase inversion. We have determined the contact angle of a water drop under oil on disks composed of compressed pigment particle mixtures for both POPR and POPB (extremes of behavior). Photos of the disks in the former case are included in Figure 1(ii) and the variation of the advancing and receding contact angles as a function of WPO is given in Figure 10 for both mixtures. In both cases, the contact angles decrease progressively upon increasing WPO indicating a decrease in the hydrophobicity of particle mixtures in line with the tendency to prefer $\mathrm{o} / \mathrm{w}$ emulsions. The vertical dashed line corresponds to WPO at emulsion phase inversion. It can be seen that this does not correspond to contact angles around $90^{\circ}$, this occurring at higher WPO. Interestingly, the apparent contact angle at phase inversion is around the same (advancing $130^{\circ}$, receding $110^{\circ}$ ) for both pigment mixtures. The contact angles reported here however are not those of individual particles but on the surface of many compressed particles which may have different properties compared to those of the primary particles affecting the contact angle. ${ }^{56}$ The possibility also exists that the surface concentration at emulsion droplet interfaces of a particular pigment type is different to its bulk concentration, although this is very difficult to verify with such small primary particles. In addition, surface roughness may influence the value of the observed contact angles. If the contact angle is $>90^{\circ}$, roughness acts to increase it whereas if $<90^{\circ}$ roughness acts to decrease it. ${ }^{57}$ Therefore, a direct correlation between the observed contact angles and emulsion type is difficult to establish. Two recent studies highlight the importance of particle roughness on both their contact angle at the oil-water interface and their effectiveness in stabilizing Pickering emulsions. ${ }^{58,59}$ As the extent of particle roughness increases, particles dispersed initially in water exhibit lower contact angles whereas those dispersed initially in oil exhibit higher contact angles, enabling the possibility to stabilize both emulsion types with one and the same particle 
type. We note also that advancing angles are always greater than receding ones. In our method of preparing emulsions, it is unknown whether oil or water contacts the particles first. We argued before that if oil contacts the particles first the advancing contact angle is adopted upon contact with water, whereas if water contacts particles first the receding contact angle is adopted upon contact with oil. ${ }^{60}$

\section{(e) Apparent surface energy of pigment particle mixtures and emulsion type}

For silica particles, we related their calculated inherent surface energies $\gamma_{s a}$ to their preference for stabilising $\mathrm{o} / \mathrm{w}$ or w/o emulsions with respect to transitional phase inversion. ${ }^{61}$ Those of low $\gamma_{s a}$ stabilised w/o emulsions whereas those of high $\gamma_{s a}$ stabilised $\mathrm{o} / \mathrm{w}$ emulsions. For emulsions stabilised by one pigment type alone, we demonstrated the propensity of the emulsion to phase invert catastrophically depending on the pigment surface energy. ${ }^{51}$ For the more hydrophobic pigments which formed a w/o emulsion, $\gamma_{s a}$ was around $20-30 \mathrm{mN} \mathrm{m}^{-1}$ as opposed to the most hydrophilic pigment PO which formed an o/w emulsion where $\gamma_{s a}$ was close to $50 \mathrm{mN} \mathrm{m}^{-1}$. We also showed that for pigments of intermediate $\gamma_{s a}\left(35-40 \mathrm{mN} \mathrm{m}^{-1}\right)$ both types of emulsion could be stabilised depending on the oil:water ratio. To account for the behavior of emulsions stabilized by pigment particle mixtures, we here estimate the apparent surface energy of particle mixtures using a method utilizing contact angles. ${ }^{61,62} \mathrm{We}$ measure the advancing and receding contact angles of a drop of different test liquids in air $\left(\theta_{l a}\right)$ on the surface of disks made from a mixture of pigment particles in which WPO is chosen to be that required for emulsion phase inversion, i.e. $\mathrm{WPO}=0.42,0.32,0.22$ and 0.12 for POPR, POPY, POPI and POPB mixtures respectively. A photo' of the disks for the four particle mixtures is given in Figure S8. Values of the air-liquid contact angles for a range of polar and non-polar liquids are given in Table 1. Using a method described by Owens and Wendt, ${ }^{63}$ the surface energy of a solid or a liquid can be divided into polar $\left(\gamma^{p}\right)$ and dispersion $\left(\gamma^{d}\right)$ contributions:

$$
\gamma=\gamma^{p}+\gamma^{d}
$$

Assuming the pigment particles are homogeneously mixed and the surface is smooth, application of Young's equation and expressing the interfacial energies by means of a geometric mean combining rule results in

$$
\frac{1}{2} \gamma_{l a}\left(1+\cos \theta_{l a}\right)=\sqrt{\gamma_{s a}^{d} \gamma_{l a}^{d}}+\sqrt{\gamma_{s a}^{p} \gamma_{l a}^{p}}
$$

in which $\gamma_{l a}$ is the liquid-air surface tension. The two unknown parameters in eq. 3 are $\gamma_{s a}^{d}$ and $\gamma_{s a}^{p}$ and can be evaluated by solving eq. 3 simultaneously for a pair of liquids although it is advisable to 
use more than two liquids of different polarity. ${ }^{64}$ We have used water, glycerol, formamide, $\alpha$ bromonaphthalene and hexadecane. Values of the terms involving liquid-air $(l a)$ are also given in Table 1. A least square calculation was carried out to determine the best combination of $\gamma_{s a}^{d}$ and $\gamma_{s a}^{p}$ that fits all the data simultaneously. The surface energy plots (goodness of fit to contact angles set against a matrix of possible values of $\gamma_{s a}^{d}$ and $\gamma_{s a}^{p}$ ) for POPY and POPB mixtures are shown in Figure 11 while those for the other two mixtures are given in Figure S9. The values that best fit all the advancing contact angles are read from the coordinates that define the peak. These solid surface energies are given in Table 2. Interestingly, apart from the mixture POPB, the surface energy of the pigment mixture corresponding to emulsion phase inversion is similar (around $44 \pm 4 \mathrm{mN} \mathrm{m}^{-1}$ ). Values of $\gamma_{s a}$ are approximately $10 \mathrm{mN} \mathrm{m}^{-1}$ higher than those above if receding contact angles are taken; e.g. see Figure S9(c) for POPB. Pease ${ }^{65}$ argued that the advancing contact angle is associated with regions on the substrate of low surface energy whereas the receding angle is associated with regions of high surface energy. It is not clear which contact angle is relevant in dictating emulsion type however.

In Figure 12, we plot how the solid surface energy, $\gamma_{s a}$ varies with the weight fraction of the hydrophilic pigment PO. Those values at $\mathrm{WPO}_{\mathrm{PO}}=0$ and 1 are for the individual pigments whereas those at $0<\mathrm{WPO}_{\mathrm{P}}<1$ are for pigment mixtures at a composition around transitional phase inversion. The values of $\gamma_{s a}$ for mixtures lie between those of the hydrophobic pigments, PY, PR, PB and PI, and that of the hydrophilic pigment PO. They vary progressively between the two extremes as wPO at phase inversion increases.

\section{Conclusions}

Mixtures of hydrophilic and hydrophobic coloured organic pigment particles have been investigated in both water and heptane and in Pickering emulsions of the two. At fixed total particle concentration and for equal oil:water ratio, transitional phase inversion of emulsions from w/o to o/w occurs on increasing the weight fraction of hydrophilic pigment PO. We show that particles of both pigments are present simultaneously at droplet interfaces. Although phase inversion occurs at different values of WPO depending on the hydrophobic pigment used, it occurs at very similar surface energies of the pigment particle mixture. The latter lies between the surface energies of the separate hydrophilic and hydrophobic pigments. Preferred droplet sizes for both w/o and o/w emulsions increase towards phase inversion in line with an increase in the extent of sedimentation or creaming respectively. All 
emulsions are ultra-stable to coalescence. In the case of POPR and POPI mixtures, a distinct change in colour of the resulting emulsions appears around phase inversion.

\section{Acknowledgements}

We are grateful to the Tertiary Education Trust Fund of Nigeria and the University of Hull for a scholarship award to SOO and Mr. A. Sinclair (University of Hull) for the cryo-SEM images. 


\section{References}

1. Pickering, S.U. CXCVI.-Emulsions. J. Chem. Soc., Trans. 1907, 91, 2001-2021.

2. Ramsden, W. Separation of solid in the surface-layers of solutions and 'suspensions' (observations on surface-membranes, bubbles, emulsion, and mechanical coagulation). Preliminary account. Proc. R. Soc. London 1903, 72, 156-164.

3. Binks, B.P. Colloidal particles at a range of fluid-fluid interfaces. Langmuir 2017, 33, 69476963.

4. Björkegren, S.; Nordstierna, L.; Törncrona, A.; Palmqvist, A. Hydrophilic and hydrophobic modifications of colloidal silica particles for Pickering emulsions. J. Colloid Interface Sci. 2017, 487, 250-257.

5. Zhu, X-F.; Zhang, N.; Lin, W-F.; Tang, C-H.; Freeze-thaw stability of pickering emulsions stabilized by soy and whey protein particles. Food Hydrocolloids 2017, 69, 173-184.

6. Nonomura, Y.; Kobayashi, N. Phase inversion of the Pickering emulsions stabilized by plateshaped clay particles. J. Colloid Interface Sci. 2009, 330, 463-466.

7. Destribats, M.; Wolfs, M.; Pinaud, F.; Lapeyre, V.; Sellier, E.; Schmitt, V.; Ravaine, V. Pickering emulsions stabilized by soft microgels: influence of the emulsification process on particle interfacial organization and emulsion properties. Langmuir 2013, 29, 12367-12374.

8. He, Y.; Wu, F.; Sun, X.; Li, R.; Guo, Y.; Li, C.; Zhang, L.; Xing, F.; Wang W.; Gao, J. Factors that affect Pickering emulsions stabilized by graphene oxide. ACS Appl. Mater. Interfaces 2013, 5, 4843-4855.

9. Saha, A.; Nikova, A.; Venkataraman, P.; John, V.T.; Bose, A. Oil emulsification using surfacetunable carbon black particles. ACS Appl. Mater. Interfaces 2013, 5, 3094-3100.

10. Wang, R.K; Reeves, R.D.; Ziegler, K. Interfacial trapping of single-walled carbon nanotube bundles. J. Am. Chem. Soc. 2007, 129, 15124-15125.

11. Briggs, N.M.; Weston, J.S.; Li, B.; Venkataramani, D.; Aichele, C.P.; Harwell, J.H.; Crossley, S.P. Multiwalled carbon nanotubes at the interface of Pickering emulsions. Langmuir 2015, $31,13077-13084$.

12. Schulman, J.H.; Leja, J. Control of contact angles at the oil-water-solid interfaces - emulsions stabilized by solid particles (BasO4). Trans. Faraday Soc. 1954, 50, 598-605.

13. Shibuichi, S.; Onda, T.; Satoh, N.; Tsujii, K. Super water-repellent surfaces resulting from fractal structure. J. Phys. Chem. 1996, 100, 19512-19517. 
14. Destribats, M.; Gineste, S.; Laurichesse, E.; Tanner, H.; Leal-Calderon, F.; Heroguez, V.; Schmitt, V. Pickering emulsions: what are the main parameters determining the emulsion type and interfacial properties? Langmuir 2014, 30, 9313-9326.

15. Binks, B.P. Particles as surfactants-similarities and differences. Curr. Opin. Colloid Interface Sci. 2002, 7, 21-41.

16. Aveyard, R.; Binks, B.P.; Clint, J.H. Emulsions stabilized solely by colloidal particles. Adv. Colloid Interface Sci. 2003, 100-102, 503-546.

17. Binks, B.P.; Lumsdon, S.O. Catastrophic phase inversion of water-in-oil emulsions stabilized by hydrophobic silica. Langmuir 2000, 16, 2539-2547.

18. Yan, N.; Gray, M.R.; Masliyah, J.H. On water-in-oil emulsions stabilized by fine solids. Colloids Surf. A 2001, 193, 97-107.

19. Sun, G.; Li, Z.; Ngai, T. Inversion of particle-stabilized emulsions to form high internal phase emulsions. Angew. Chem. Int., Ed. 2010, 49, 2163-2166.

20. Binks, B.P.; Murakami, R.; Armes, S.P. Temperature-induced inversion of nanoparticlestabilized emulsions. Angew. Chem. Int., Ed. 2005, 117, 4873-4876.

21. Binks B.P.; Lumsdon, S.O. Transitional phase inversion of solid-stabilized emulsions using particle mixtures. Langmuir 2000, 16, 3748-3756.

22. Saha, A.; John, V.T.; Bose, A. In situ assembly of hydrophilic and hydrophobic nanoparticles at oil-water interfaces as a versatile strategy to form stable emulsions. ACS Appl. Mater. Interfaces 2015, 7, 21010-21014.

23. Nallamilli, T.; Mani, E.; Basavaraj, M.G. A model for the prediction of droplet size in Pickering emulsions stabilized by oppositely charged particles. Langmuir 2014, 30, 9336-9345.

24. Liu, T.; Seiffert, S.; Thiele, J.; Abate, A.R.; Weitz, D.A.; Richtering, W. Non-coalescence of oppositely charged droplets in $\mathrm{pH}$-sensitive emulsions. Proc. Natl. Acad. Sci. U.S.A. 2012, 109, 384-389.

25. Abend, S.; Bonnke, N.; Gutschner, U.; Lagaly, G. Stabilization of emulsions by heterocoagulation of clay minerals and layered double hydroxides. Colloid Polym. Sci. 1998, 276, 730-737.

26. Nallamilli, T.; Binks, B.P.; Mani, E.; Basavaraj, M.G. Stabilization of Pickering emulsions with oppositely charged latex particles: influence of various parameters and particle arrangement around droplets. Langmuir 2015, 31, 11200-11208.

27. Horozov, T.S.; Aveyard, R.; Clint, J.H.; Binks, B.P. Order-disorder transition in monolayers of modified monodisperse silica particles at the octane-water interface. Langmuir 2003, 19, 2822-2829. 
28. Monteux, C.; Jung, E.; Fuller, G.G. Mechanical properties and structure of particle coated interfaces: influence of particle size and bidisperse 2D suspensions. Langmuir 2007, 23, 39753980.

29. Ma, H.; Perea, B.; Dai, L.L. Study of two-component colloidal particles at air/water interfaces using Langmuir-Blodgett techniques. Colloids Surf. A 2010, 372, 61-65.

30. Law, A.D.; Auriol, M.; Smith, D.; Horozov, T.S.; Buzza, D.M.A. Self-assembly of twodimensional colloidal clusters by tuning the hydrophobicity, composition, and packing geometry. Phys. Rev. Lett. 2013, 110, 138301.

31. Rabideau B.D.; Bonnecaze, R.T. Computational predictions of stable 2D arrays of bidisperse particles. Langmuir 2005, 21, 10856-10861.

32. Rabideau B.D.; Bonnecaze, R.T. Computational study of the self-organization of bidisperse nanoparticles. Langmuir 2004, 20, 9408-9414.

33. Dai, L.L.; Tarimala, S.; Wu, C-Y.; Guttula, S.; Wu, J. The structure and dynamics of microparticles at Pickering emulsion interfaces. Scanning 2008, 30, 87-95.

34. Ma, H.; Dai, L.L. Particle self-assembly in ionic liquid-in-water Pickering emulsions. Langmuir 2011, 27, 508-512.

35. Chantrapornchai, W.; Clydesdale, F.; McClements, D.J. Influence of droplet characteristics on the optical properties of colored oil-in-water emulsions. Colloids Surf. A 1999, 155, 373-382.

36. Chanamai, R.; McClements, D.J. Prediction of emulsion color from droplet characteristics: dilute monodisperse oil-in- water emulsions. Food Hydrocolloids 2001, 15, 83-91.

37. Park, B-G.; Park, I-J.; Han, J-S.; Lee, S-M.; Lee, C-G.; Ha, C-S. Characterization of optical properties in water-in-oil emulsion. J. Disp. Sci. Technol. 2013, 34, 560-565.

38. Clydesdale, F. Colour as a factor in food choice. Crit. Rev. Food Sci. Nutr. 1993, 33, 83-101.

39. Hutching, J.B. Food Colour and Appearance, Blackie, London, 1994.

40. Kerker, M. The Scattering of Light, Academic Press, New York, 1969.

41. Choudhury, A.K.R. Principle of Colour Appearance and Measurement, Vol. 1, Woodhead Publishing, Cambridge, 2014.

42. Zollinger, H. Colour Chemistry: Synthesis, Properties, and Applications of Organic Pigments, $3^{\text {rd }}$ ed.,Wiley-VCH, Switzerland, 2003.

43. Christie, R.M. Colour Chemistry, $2^{\text {nd }}$ ed., Royal Society of Chemistry, Cambridge, 2001.

44. Peter, T.; Freeman, H.S. Physicochemical Principles of Colour Chemistry, Blackie, Glasgow, Vol. 4, 1996.

45. Qu, D.; Duncan, J.W. Study on pigment dispersion in color cosmetics: Milling process and scale-up. J. Cosmet. Sci. 2000, 51, 323-341. 
46. Fu, J.M.; Li, Y.; Guo, J.L. Optical behavior of organic pigments in aqueous dispersions and its application. J. Colloid interface Sci. 1998, 202, 450-455.

47. Herbst, W.; Hunger, K. Industrial Organic Pigments, $3^{\text {nd }}$ ed., VCH, Germany, 2004.

48. Baez, E.; Quazi, N.; Ivanov, I.; Bhattacharya, S.N. Stability study of nanopigment dispersions, Adv. Powder Technol. 2009, 20, 267-272.

49. Gregory, P. High-Technology Applications of Organic Colorants, Plenum Press, New York, 1991.

50. Bai, P.F.; Hayes, R.A.; Jin, M.L.; Shui, L.L.; Yi, Z.C.; Wang, L.; Zhang, X.; Zhou, G.F. Review of paper-like display technologies. Prog. Electromagn. Res. 2014, 147, 95-116.

51. Binks, B.P.; Olusanya, S.O. Pickering emulsions stabilized by coloured organic pigment particles. Chem. Sci. 2017, 8, 708-723.

52. Binks, B.P.; Sekine, T.; Tyowua, A.T. Dry oil powders and oil foams stabilised by fluorinated clay platelet particles. Soft Matter 2014, 10, 578-589.

53. Binks, B.P.; Fletcher, P.D.I.; Holt, B.L.; Beaussoubre, P.; Wong, K. Phase inversion of particlestabilised perfume oil-water emulsions: experiment and theory. Phys. Chem. Chem. Phys. 2010, 12, 11954-11966.

54. Binks, B.P.; Johnston, S.K.; Sekine, T.; Tyowua, A.T. Particles at oil-air surfaces: powdered oil, liquid oil marbles and oil foam. ACS Appl. Mater. Interfaces 2015, 7, 14328-14337.

55. Binks, B.P.; Lumsdon, S.O. Influence of particle wettability on the type and stability of surfactant free emulsions. Langmuir 2000, 16, 8622-8631.

56. de Folter, J.W.J.; van Ruijven, M.W.M.; Velikov, K.P. Oil-in-water Pickering emulsions stabilized by colloidal particles from the water-insoluble protein zein. Soft Matter 2012, 8, 6807-6815.

57. Wenzel, R.N. Resistance of solid surfaces to wetting by water. Ind. Eng. Chem. 1936, 28, 988994.

58. San-Miguel, A.; Behrens, S.H. Influence of nanoscale particle roughness on the stability of Pickering emulsions. Langmuir 2012, 28, 12038-12043.

59. Zanini, M.; Marschelke, C.; Anachkov, S.E.; Marini, E.; Synytska, A.; Isa, L. Universal emulsion stabilization from the arrested adsorption of rough particles at liquid-liquid interfaces. Nature Commun. 2017, 8, 15701.

60. Binks, B.P.; Philip, J.; Rodrigues, J.A. Inversion of silica-stabilized emulsions induced by particle concentration. Langmuir 2005, 21, 3296-3302. 
61. Binks, B.P.; Clint, J.H. Solid wettability from surface energy components: relevance to Pickering emulsions. Langmuir 2002, 18, 1270-1273.

62. Clint, J.H. Adhesion and components of solid surface energies. Curr. Opin. Colloid Interface Sci. 2001, 6, 28-33.

63. Owens, D.K.; Wendt, R.C. Estimation of the surface free energy of polymers. J. Appl. Polym. Sci. 1969, 13, 1741-1747.

64. Clint, J.H.; Wicks, A.C. Adhesion under water: surface energy considerations. Int. J. Adhes. Adhes. 2001, 21, 267-273.

65. Pease, D.C. The significance of the contact angle in relation to the solid surface. J. Phys. Chem. 1945, 49, 107-110. 
Table 1. Dispersion, $\gamma_{l a}^{d}$ and polar, $\gamma_{l a}^{p}$ components with the corresponding $\gamma_{l a}$ of probe liquids at 25 ${ }^{\circ} \mathrm{C}$ (from ref. 64) as well as the three-phase equilibrium advancing and receding air-liquid contact angles measured on disks made from the pigment particle mixture at WPO around emulsion phase inversion for (a) POPR (WPO =0.42), (b) POPY (WPO = 0.32), (c) POPI (WPO = 0.22) and (d) POPB $(\mathrm{WPO}=0.12)$.

\section{Contact angle/ ${ }^{\circ}\left( \pm 3^{\circ}\right)$}

\begin{tabular}{|c|c|c|c|c|c|c|c|c|c|c|c|}
\hline \multirow[b]{2}{*}{ Liquid } & \multicolumn{3}{|c|}{$\begin{array}{l}\text { Surface tension/ } \\
\mathrm{mN} \mathrm{m}^{-1}\end{array}$} & \multicolumn{2}{|c|}{ POPR } & \multicolumn{2}{|c|}{ POPY } & \multicolumn{2}{|c|}{ POPI } & \multicolumn{2}{|c|}{ POPB } \\
\hline & $\gamma_{l a}^{d}$ & $\gamma_{l a}^{p}$ & $\gamma_{l a}$ & Adv. & Rec. & Adv. & Rec. & Adv. & Rec. & Adv. & Rec. \\
\hline Water & 21.6 & 50.5 & 72.1 & 72 & 52 & 83 & 61 & 64 & 44 & 73 & 51 \\
\hline Glycerol & 34.0 & 30.0 & 64.0 & 61 & 46 & 67 & 47 & 56 & 34 & 61 & 44 \\
\hline Formamide & 39.0 & 19.0 & 58.0 & 40 & 25 & 52 & 35 & 44 & 26 & 57 & 39 \\
\hline $\begin{array}{l}\alpha- \\
\text { Bromonap } \\
\text { hthalene }\end{array}$ & 44.4 & 0.0 & 44.4 & $<5$ & $<2$ & $<5$ & $<2$ & $<5$ & $<2$ & $<5$ & $<2$ \\
\hline $\begin{array}{l}n \text { - } \\
\text { Hexadecane }\end{array}$ & 27.8 & 0.0 & 27.8 & $<5$ & $<2$ & $<5$ & $<2$ & $<5$ & $<2$ & $<5$ & $<2$ \\
\hline
\end{tabular}

Table 2. Apparent surface energy for pigment particle mixture as well as their corresponding polar and dispersion components determined at WPO around emulsion phase inversion calculated using advancing contact angles.

\begin{tabular}{lcccc}
\hline & \multicolumn{4}{c}{ Pigment surface energy/mN m-1 } \\
\hline Mixture & WPO & $\gamma_{s a}^{d}$ & $\gamma_{s a}^{p}$ & $\gamma_{s a}$ \\
POPR & 0.42 & 42.1 & 4.8 & $46.9 \pm 3.1$ \\
POPY & 0.32 & 41.6 & 2.0 & $43.6 \pm 3.0$ \\
POPI & 0.22 & 27.2 & 15.2 & $42.4 \pm 3.5$ \\
POPB & 0.12 & 25.1 & 11.0 & $36.1 \pm 3.2$ \\
& & & & \\
\hline
\end{tabular}


Figure 1. (i) Photos showing the appearance of vessels containing dry powder of pigment mixture at fixed total particle mass (0.1 g) but varying WPO (given) for (a) POPR, (b) POPY, (c) POPI and (d) POPB. (ii) Disks made from the dry powder of POPR particle mixture at different WPO given.
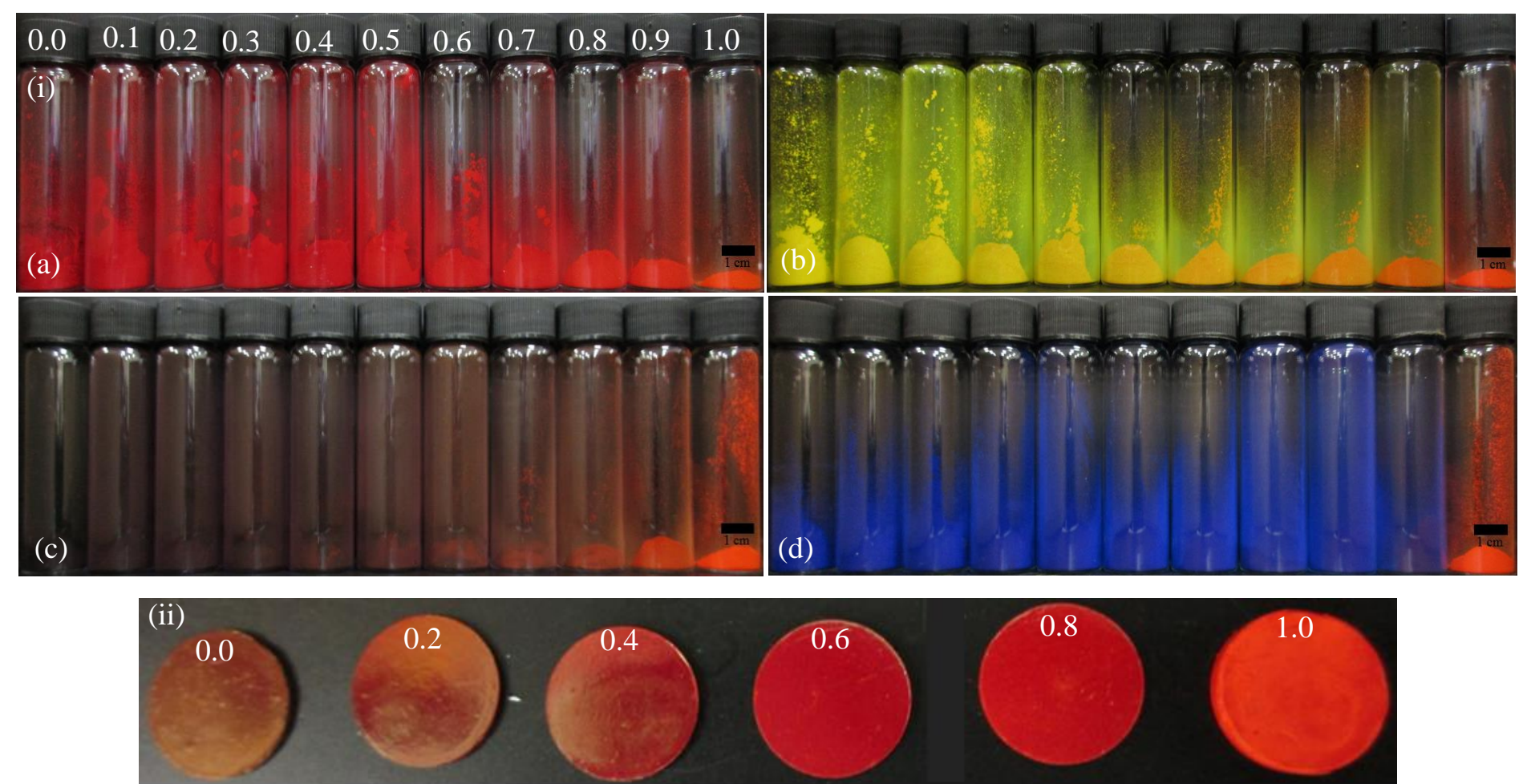
Figure 2. Photos of vessels showing the appearance before and after agitation of either water or $n$ heptane with $50 \mathrm{mg}$ of mixed pigment particles at WPO $=0.1$ (left) and 0.6 (right).

At rest
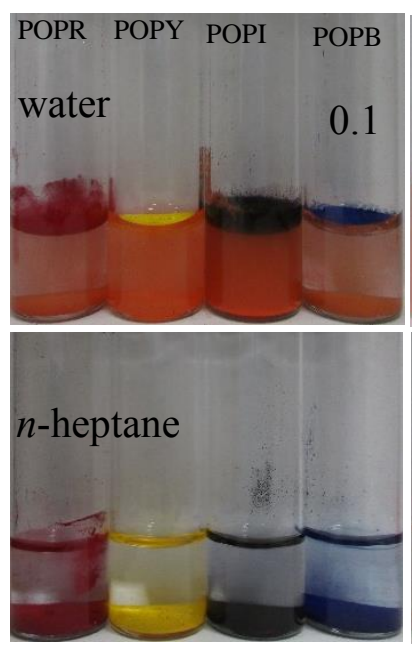

After shaking
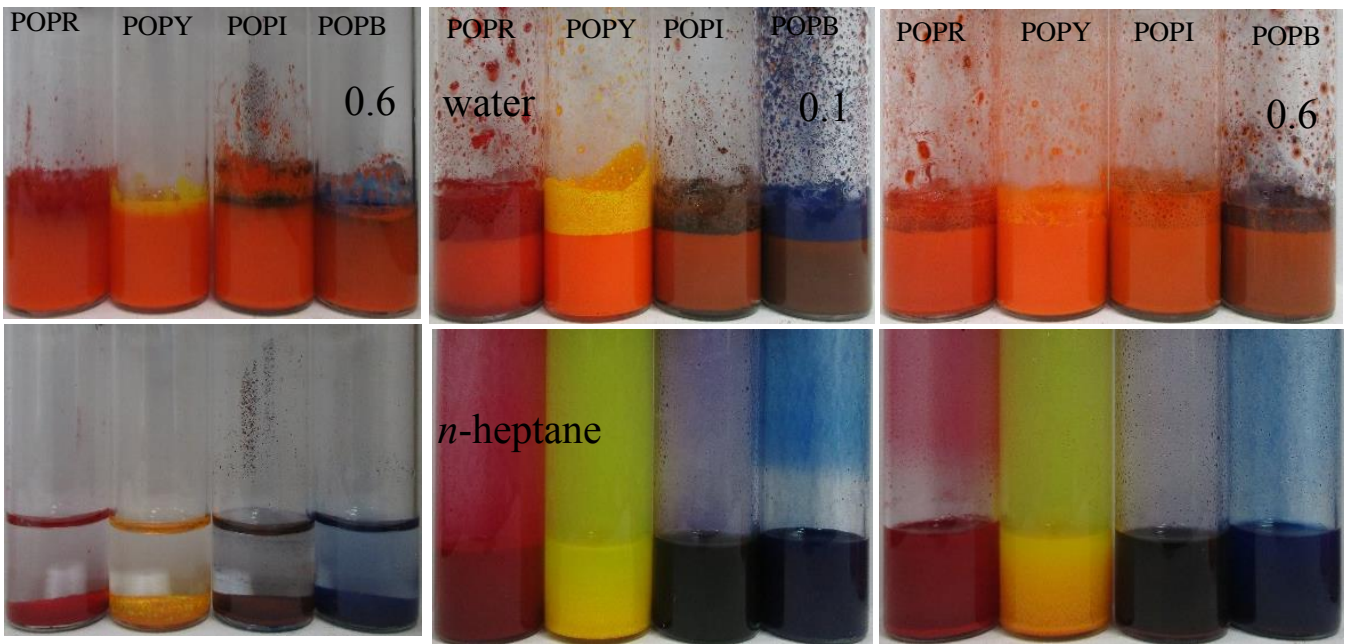
Figure 3. Photos of vessels after 30 min containing $n$-heptane-water emulsions (1:1) stabilized by particle mixture with varying WPO (given, same for all mixtures) but fixed total particle concentration (1 wt.\%) for (a) POPR, (b) POPY, (c) POPI and (d) POPB. Vertical dashed line indicates position of transitional phase inversion.

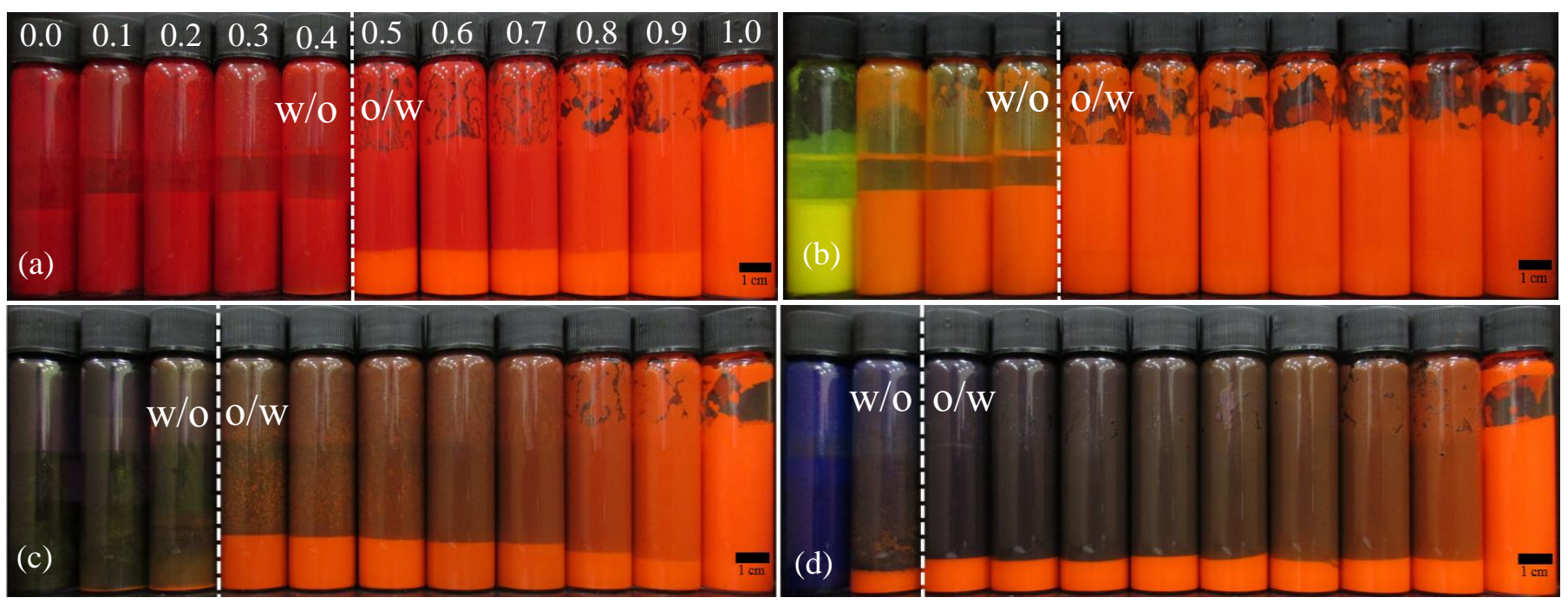


Figure 4. Conductivity of $n$-heptane-water emulsions (1:1) described in Figure 3 containing a total of $1 \mathrm{wt} . \%$ particles as a function of WPO. Vertical dashed lines indicate transitional phase inversion.

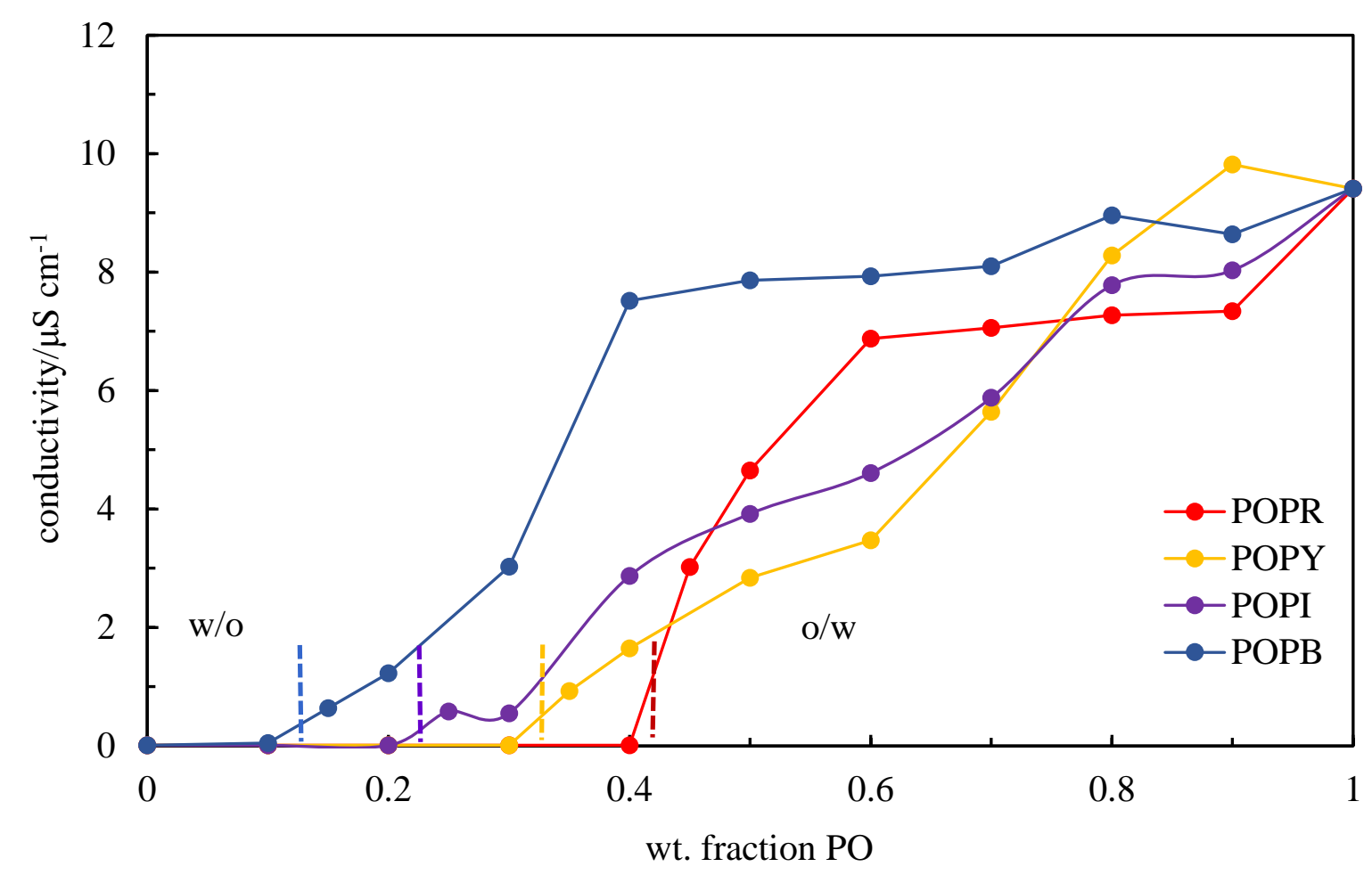


Figure 5. (a) Fraction of $n$-heptane resolved with time due to either sedimentation in w/o emulsions or coalescence in o/w emulsions and (b) fraction of water released with time due to coalescence in w/o emulsions or creaming in o/w emulsions for mixtures of PO and PI containing a total of $1 \mathrm{wt} \%$ particle but varying $\mathrm{WPO}_{\mathrm{PO}}$ (given). Emulsions are w/o for $\mathrm{WPO}_{\mathrm{PO}} \leq 0.2$ and $\mathrm{o} / \mathrm{w}$ for $\mathrm{WPO}_{\mathrm{PO}} \geq 0.3$.
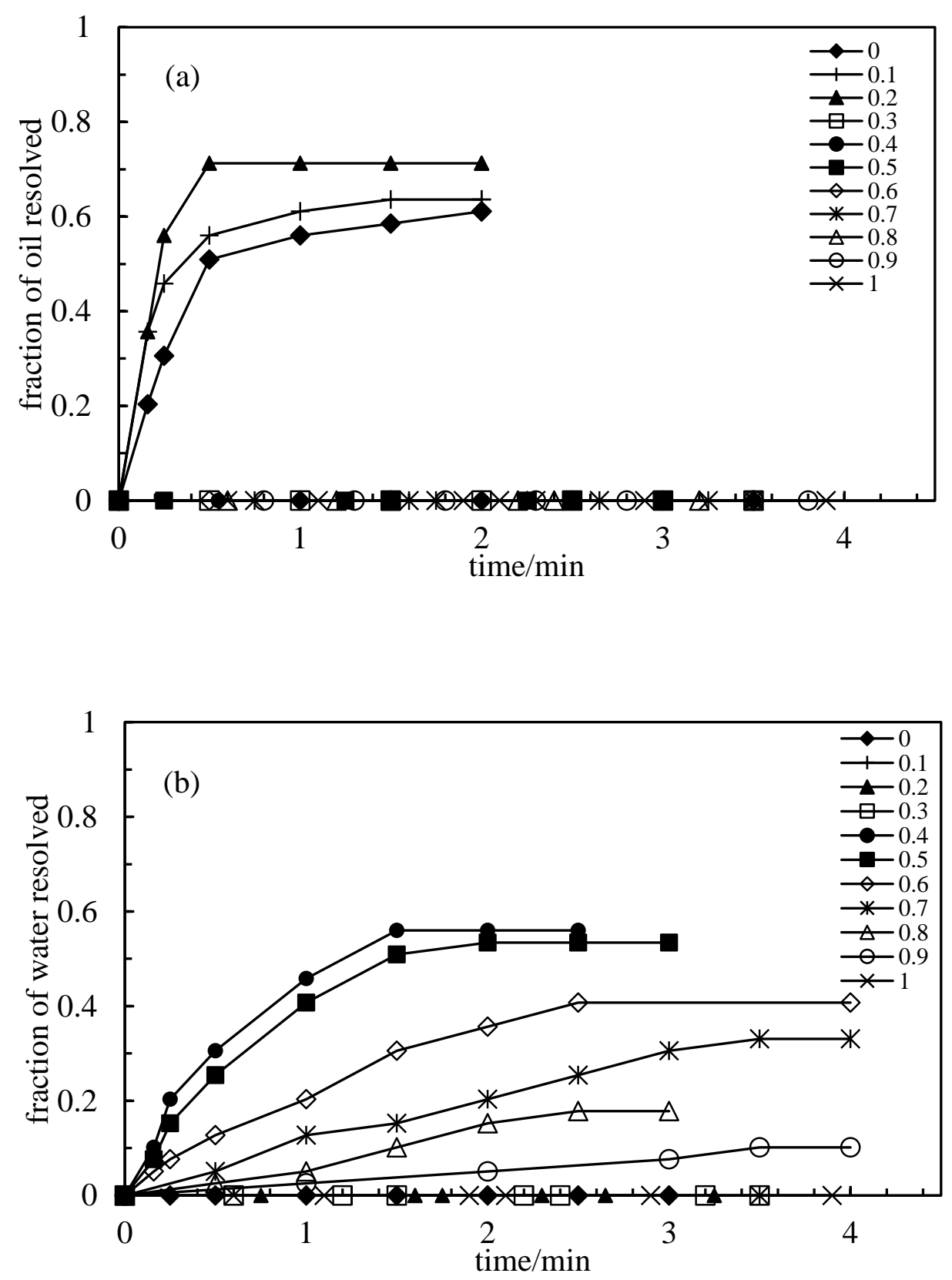
Figure 6. Fraction of $n$-heptane (filled circles) and water (open circles) resolved after 6 months from $n$-heptane-water emulsions as a function of WPO for mixtures of (a) POPR, (b) POPY, (c) POPI and (d) POPB.
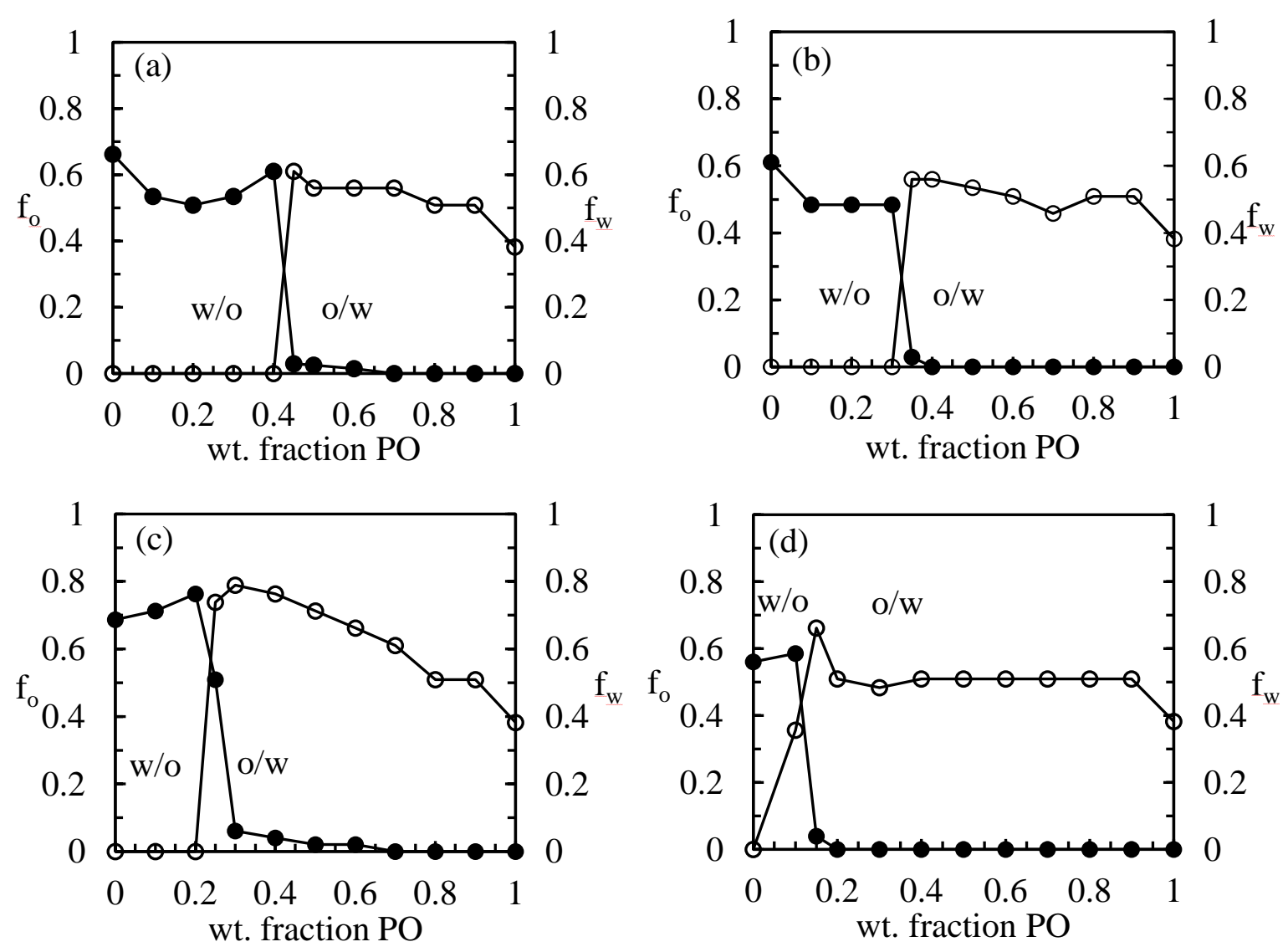
Figure 7. Optical micrographs of $n$-heptane-water emulsions after $20 \mathrm{~min}$ at different $\mathrm{W}_{\mathrm{PO}}$ (given) with a total of 1 wt.\% particles for mixtures of (a) POPR, (b) POPY, (c) POPI and (d) POPB.
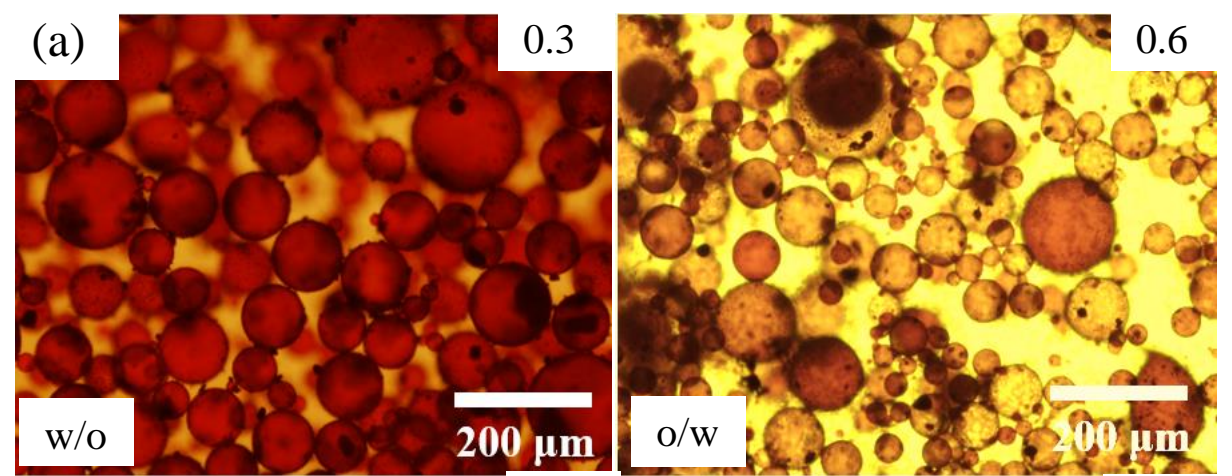

(b)
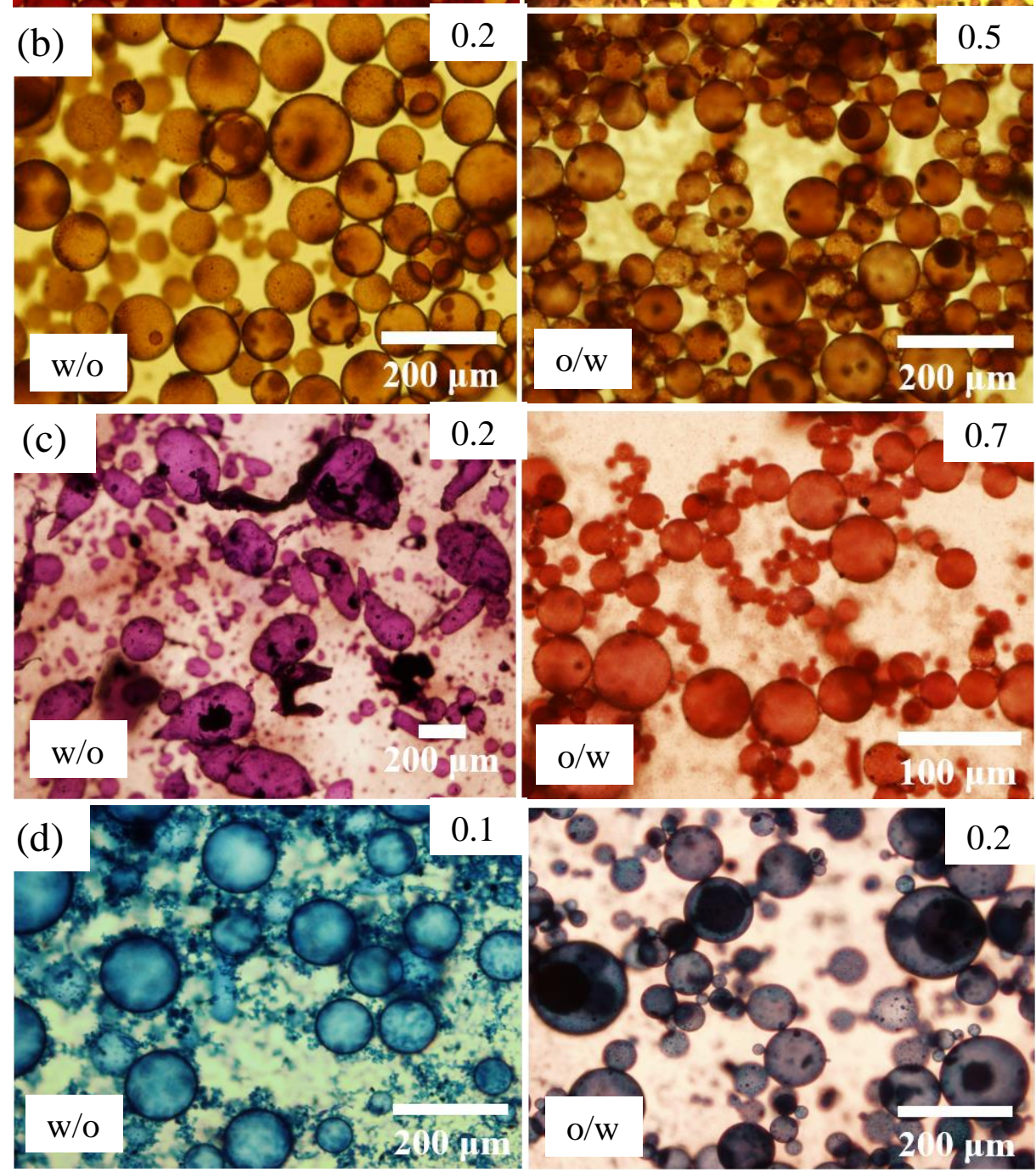
Figure 8. Cryo-SEM images of the surface of w/o emulsions for (a) POPY ( $\mathrm{W}_{\mathrm{PO}}=0.3$ ) and (b) POPI $\left(\mathrm{WPO}_{\mathrm{PO}}=0.2\right)$ and of o/w emulsions for $(\mathrm{c}) \mathrm{POPR}\left(\mathrm{WPO}_{\mathrm{PO}}=0.5\right),(\mathrm{d})$ POPY (WPO $\left.=0.6\right)$ and (e) POPB (wPO $=0.7)$.
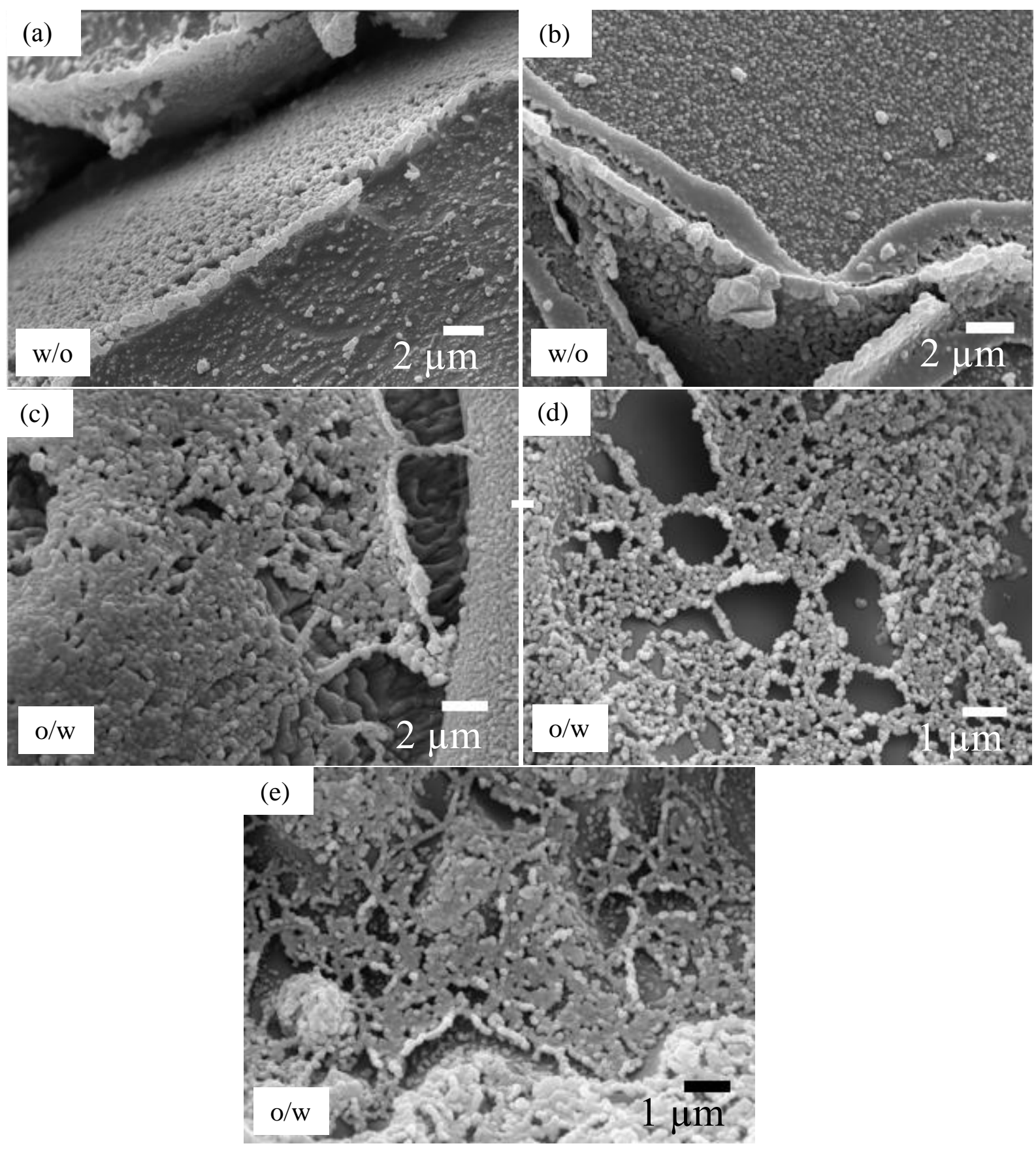
Figure 9. Variation of initial mean drop diameter with WPO $_{P}$ for $n$-heptane-water emulsions stabilized by (a) POPR, (b) POPY, (c) POPI and (d) POPB particle mixtures. Vertical dotted line signifies transitional phase inversion.
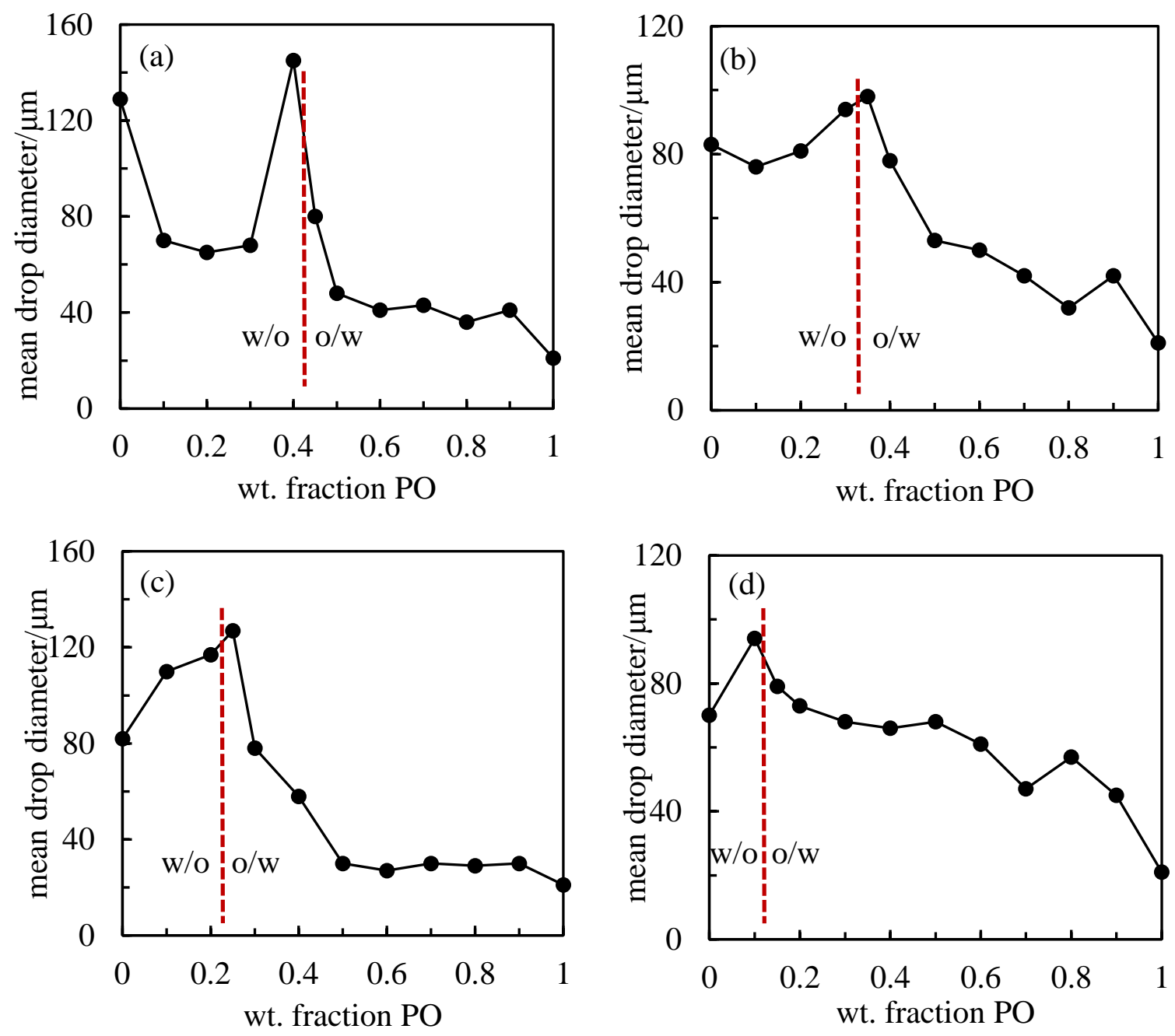
Figure 10. Variation of advancing (filled circles) and receding (open circles) contact angles of a water drop under $n$-heptane measured on disks made from pigment particle mixtures at different WPO for (a) POPR and (b) POPB. Vertical dashed line indicates the position of transitional phase inversion in emulsions.
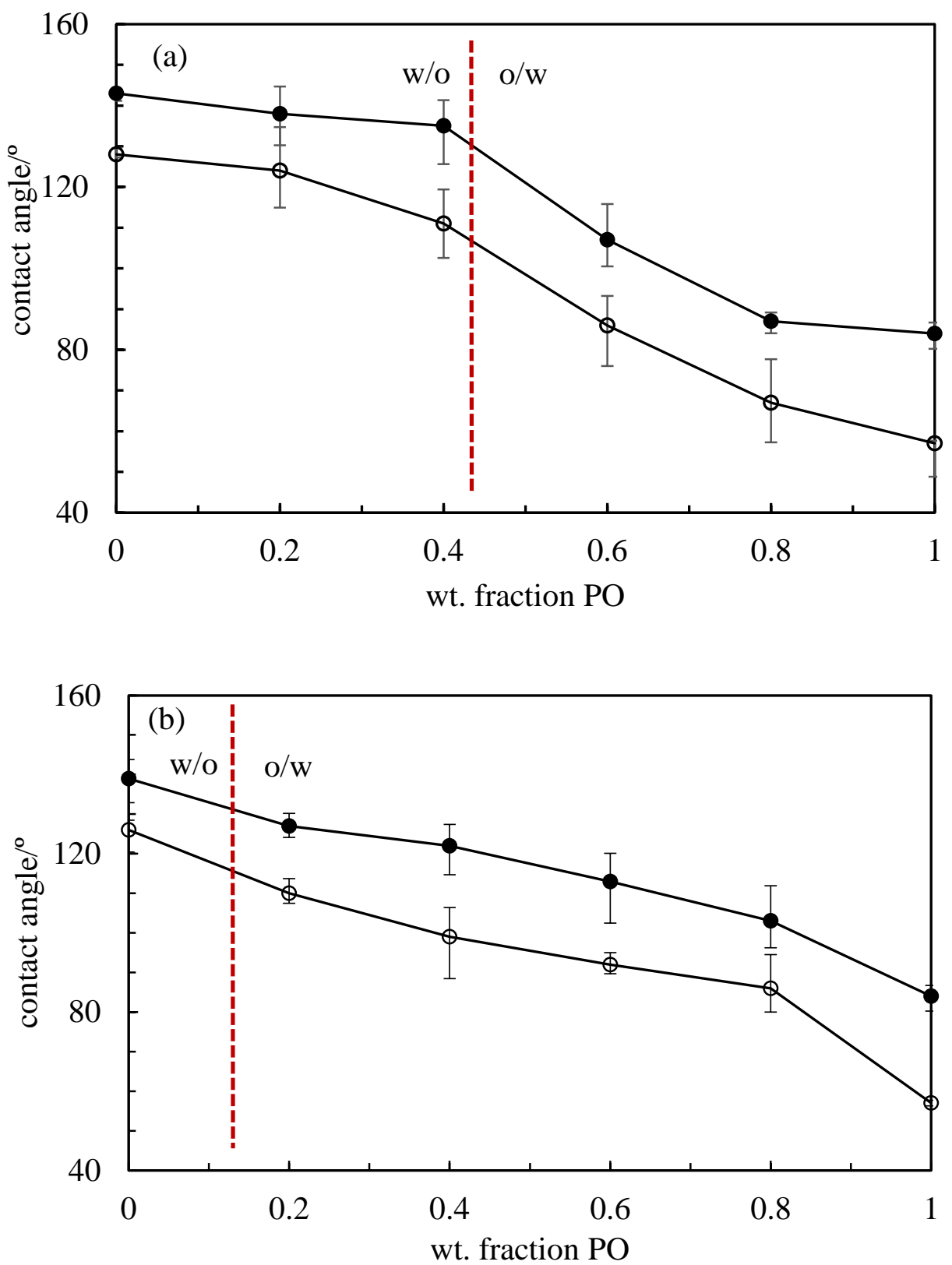
Figure 11. 3-D surface energy plots for disks of pigment particle mixtures for (a) POPY ( $\left.\mathrm{W}_{\mathrm{PO}}=0.32\right)$ and $(b)$ POPB $\left(\mathrm{WPO}_{\mathrm{P}}=0.12\right)$ using advancing contact angle.
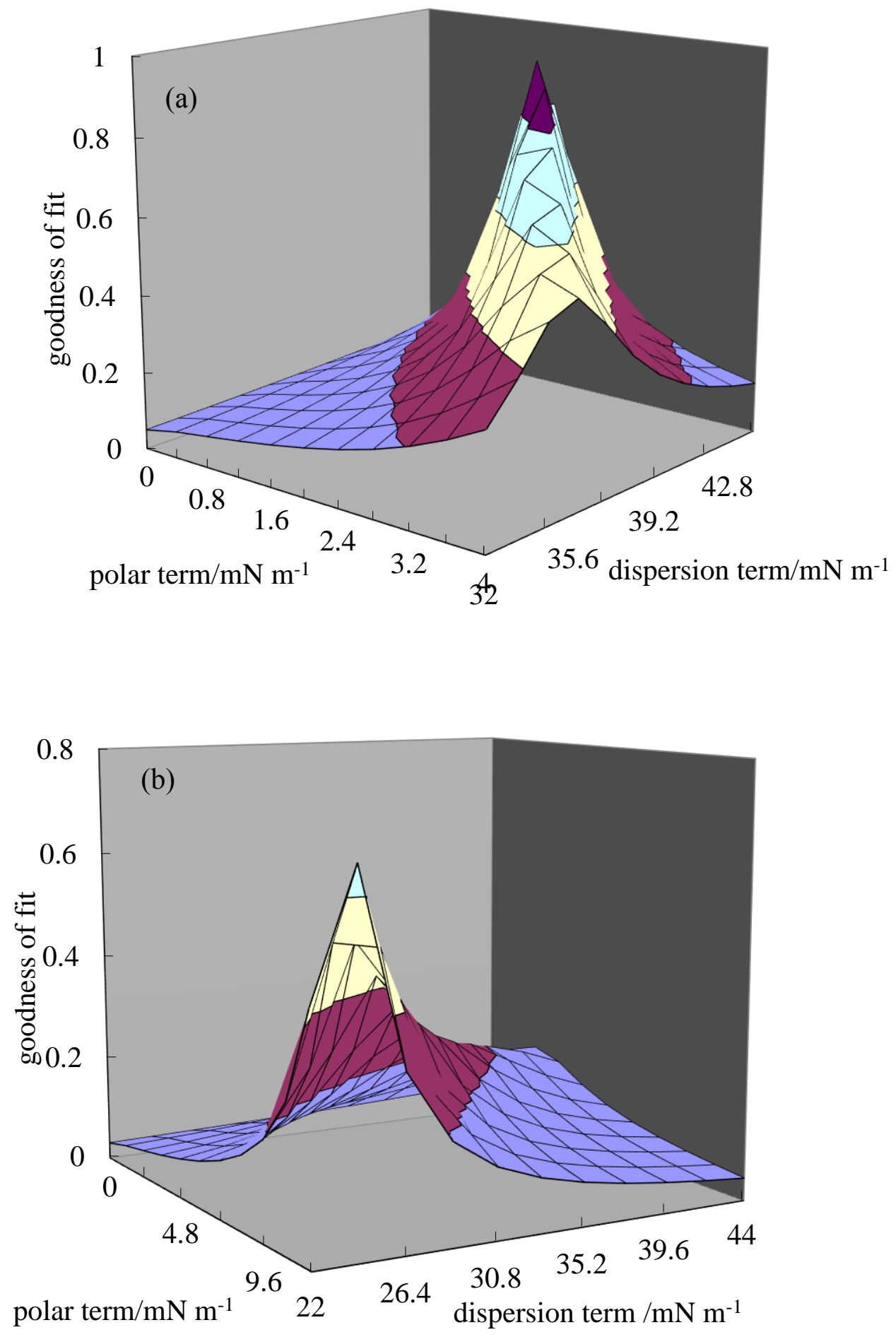
Figure 12. Pigment surface energy (using advancing contact angle) versus weight fraction of PO for systems containing a single pigment (circles) and systems containing a pigment mixture at WPO around emulsion phase inversion (triangles).

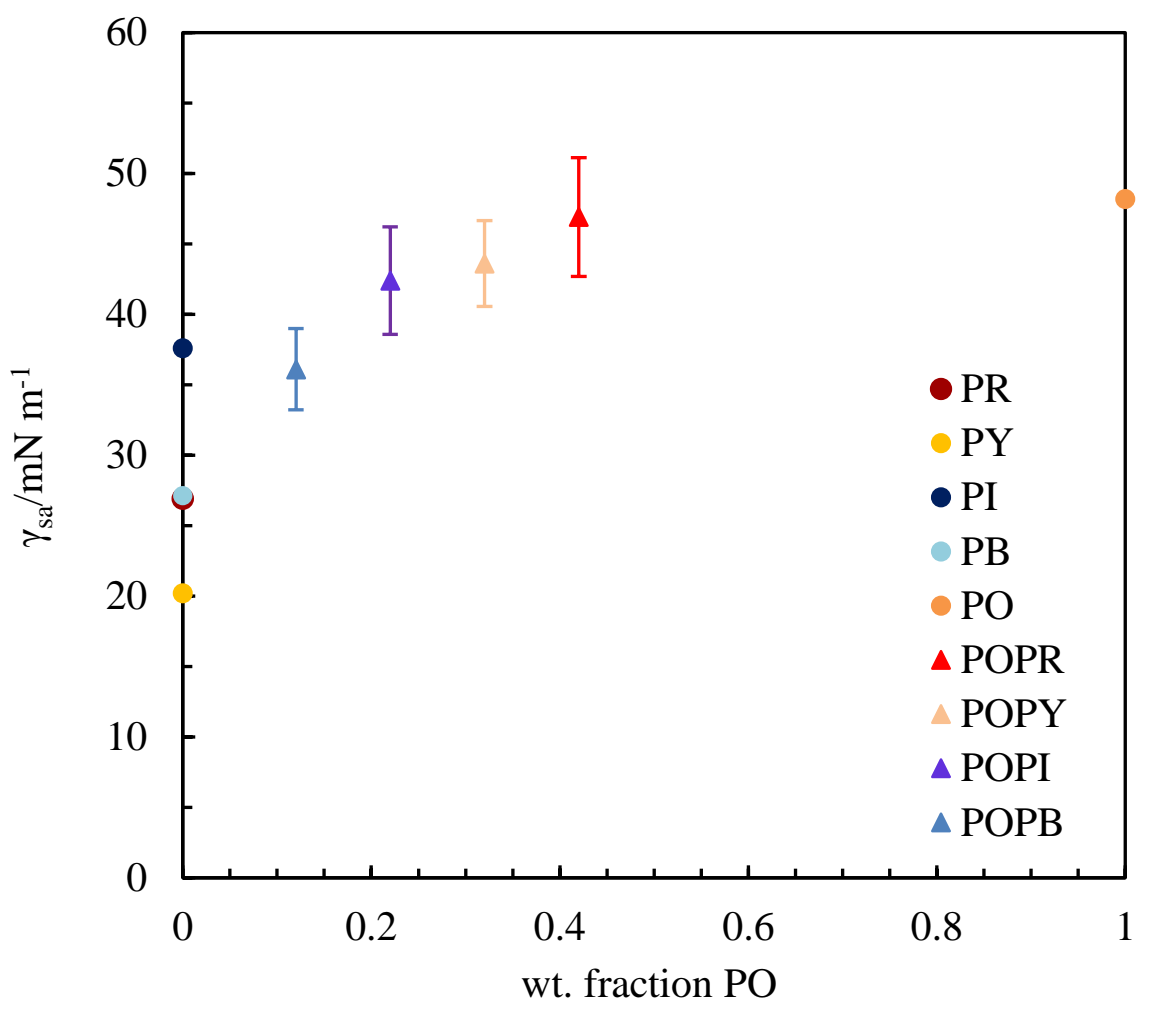

